\title{
EDITORIAL
}

\section{ANAPLASTOLOGÍA: UN NUEVO DESARROLLO DE LA FACULTAD DE ESTOMATOLOGÍA ROBERTO BELTRÁN}

El avance del conocimiento científico y la creciente demanda de profesionales más capacitados para ofrecer la mejor solución a los diferentes cuadros patológicos que ocurren en la zona anatómica denominada buco maxilofacial ha conducido a que los profesionales de la odontología moderna, no sólo se dediquen al cuidado de los dientes y tejidos de soporte sino también estén involucrados en la solución de las malformaciones oro- faciales y en la prevención, diagnóstico y tratamiento de todas las enfermedades de la mucosa oral, huesos maxilares y glándulas salivales. Asimismo, el odontólogo bien formado tiene que entender los aspectos psicológicos, sociales y económicos que influyen en la aparición de diferentes cuadros patológicos de la boca y estructuras adyacentes.

El campo clínico odontológico actual es en realidad la estomatología moderna que comprende un mayor desarrollo de áreas existentes y nuevas como son: medicina y patología oral y maxilofacial, radiología oral y maxilofacial, cirugía oral y maxilofacial, rehabilitación oral, odontología restauradora y estética, periodoncia, implantología, endodoncia, odontología pediátrica, odontología para pacientes con necesidades especiales y gerontología. Por otro lado siguen surgiendo nuevas especialidades o campos de trabajo para el odontólogo como es la anaplastología.

La anaplastología nace por el sentimiento natural que tiene el ser humano de recuperar su integridad física perdida y mantener la semejanza con sus congéneres. Se puede definir como el arte o ciencia de la restauración de malformaciones, ausencias o pérdida de partes de la cara y del cuerpo por medios artificiales. La principal causa no congénita de pérdida de la integridad de un área anatómica, la constituyen los accidentes de tránsito, puesto que en la mayoría de ellos se producen lesiones tan severas en el rostro que conducen a la pérdida total o parcial de los maxilares, nariz, ojos, orejas y de otros tejidos vecinos. Otro factor importante es la cirugía oncológica de la región maxilofacial. La pérdida de estructuras anatómicas puede desencadenar un proceso sicopatológico, con cuadros de depresión o ansiedad e incluso comportamientos suicidas.

Hoy esta problemática se puede solucionar con la participación de diferentes especialistas donde destacan el protesista y el implantólogo oral quienes al lado del cirujano maxilofacial, el plástico, el otorrinolaringólogo y el oculista, empleando novedosas técnicas y excelentes materiales ahora disponibles, pueden restaurar con éxito muchos problemas estéticos y funcionales de la región facial, que hasta hace unos pocos años no tenían solución o su solución era muy pobre.

El hombre en el transcurso de su historia, en todas las diferentes civilizaciones y pueblos, ha buscado la perfección. En nuestros días, el desarrollo de la anaplastología ofrece una opción 
terapéutica de posibilidades estéticas sorprendentes, ya que además integra a los enfermos en su entorno sociolaboral al disminuir el trauma psíquico resultado de la ausencia parcial o total de una parte de la cara. La disminución de la ansiedad del enfermo y alargamiento de la vida se puede calificar de auténtico bienestar social y salud pública, labor que consideramos compete a la universidad y específicamente a la Facultad de Estomatología Roberto Beltrán, en el ámbito de su competencia que es la región buco maxilofacial.

Una pregunta fundamental que debemos hacernos antes de emprender la tarea de desarrollar la anaplastología en nuestro país es si se necesita formar anaplastólogos o si ya existen este tipo de profesionales. El análisis de este campo en nuestro medio nos indica que sí existen profesionales que de alguna forma confeccionan aditamento protésicos somáticos pero nos atrevemos a señalar que lo hacen con insuficiente formación técnico científica y sin la utilización de los materiales adecuados. Esto, podemos decir es comparable con lo ocurrido con los implantes dentales. La era de la implantología moderna se inició en el año 1982 cuando en Toronto, Branemark presentó al mundo odontológico la óseo integración y su implante de titanio en forma de tornillo, avalado por un seguimiento clínico de 10 años, sin embargo en el Perú no llega a una década la utilización de este moderno método de rehabilitación de la función masticatoria. En otras palabras, comenzamos muy tarde.

Al cumplir la Universidad Cayetano Heredia 50 años de eficiente y fructífera vida académica, la Facultad de Estomatología no solamente se siente orgullosa de pertenecer a esta magnífica institución y celebra con mucha satisfacción y júbilo los innumerables logros alcanzados, sino que se siente en el deber de proponer nuevos desarrollos, como es el programa de Anaplastología, que a no dudar repercutirá y beneficiará a muchos individuos de la sociedad peruana, que en forma congénita o adquirida tienen ausencia de una parte de su rostro y les permita llevar una vida personal y anímica dentro de la normalidad.

Dr. Wilson Delgado A.

Director 